\title{
Torque-Assisting Compressed Air Energy Storage Hydraulic Wind Drivetrains
}

\author{
Moyuan Chen, Sofia M. Santos and Afshin Izadian, Senior Member, IEEE \\ Energy Systems and Power Electronics Laboratory \\ Purdue School of Engineering and Technology \\ Indianapolis, IN 46202 \\ aizadian@iupui.edu
}

\begin{abstract}
In this paper, Compressed Air Energy Storage (CAES) as a popular technology for wind energy storage, is mathematically integrated with a hydraulic wind power system. Hydraulic machinery as prime-movers is utilized to gain the benefit of eliminating costly and heavy gearboxes. The goal of this work is to improve the power delivery performance while maintaining a stable frequency generation in a $600 \mathrm{~kW}$ hydraulic wind power system. Simulation results demonstrate that the integration of compressed air energy storage has improved the quality of power delivery such that the maximum power demand can be delivered while maintaining the frequency under variable wind speeds.
\end{abstract}

\section{INTRODUCTION}

$\mathrm{W}$ indenergy, as green and sustainable, has become one of the most important renewable energy technologies. A traditional wind power system typically consists of a gearbox inside the wind turbine nacelle, to transfer from the energy of wind to mechanical force to rotate the generator [1]. In recent years, a hydraulic wind power system has been developed, in which the role of the conversional gearbox is replaced by a hydraulic pump which has much less weight. The wind energy is converted to mechanical driving force of a hydraulic motor which combines with a generator and together they are located on ground level. During the power transfer, high density fluid as an intermediate medium transfers energy through high pressure pipe from the wind turbine to the hydraulic motor [24]. In this system, both the generator and the gearbox are eliminated from a traditional nacelle. Therefore, the capacity factor can be increased and this new wind power system benefits largely from reducing the construction, operating and maintenance costs [4-7]. However, even with the new technology the intermittent behavior of the wind power can be sensed at the load. Energy storage techniques are utilized to mitigate this problem.

Compressed Air Energy Storage (CAES) has been being developed and coupled with wind power system for energy storage. Its capacity has reached large volume and has been implemented in practical applications [7-10].A typical CAES used in a wind power system is to store the surplus electrical energy by means of compressed air inside an air tank during strong wind periods, and to supply electricity by sending high pressure air to a gas turbine generator when the wind speed is low and the power demand is high [11-12]. Normally, when wind speed changes, the shaft rotational speed and its generated power and torque also change correspondingly. Thus, as a consequent, the generator frequency which is determined by the shaft speed deviates from its reference, $60 \mathrm{~Hz}$ in a standalone operation. When connected to grid, the amount of power injected to the grid is determined by the power of prime mover. If no energy storage or backup source is available, to keep the generator frequency constant (in a standalone mode), the load demand should be constantly adjusted. Such system transfers the wind power intermittency directly to the customer and therefore is less desirable.

In this paper, a $600 \mathrm{~kW}$ hydraulic wind power system is equipped with a CAES. The overall system operation is mathematically modeled and its operation and effects on power delivery improvements are studied. Main goal of the control system is to maintain $60 \mathrm{~Hz}$ generator frequency while the integrated hydraulic wind and CAES can deliver the power on demand. Dynamics of CAES, including status of the mass flow rate, pressure, charge and discharge profiles along with respective input and output power are demonstrated. Simulation results demonstrate the power delivery of the integrated system and the frequency of generators under variable wind speed and load demand.

\section{HYDRAULIC WIND POWER SYSTEM}

Wind power is harvested using a high-torque low speed turbine. Intermittent wind speed introduces hydraulic flow fluctuations from the prime mover that eventually changes the electric power flow in the system[13].

Steady electric power generation requires a steady flow of pressurized hydraulic medium to the primary hydraulic motor. Proportional valves are used to regulate and control the hydraulic flow to manage the electric power generation.

Wind power drives a fixed displacement pump. The pump provides fluid under a wide range of working pressure in the system. Figure 1 shows the overall system configuration. The flow is passed to a variable displacement motor. This motor is connected directly to the shaft of the generator and the compressed air energy storage unit[13]. In reality, there are other hydraulic components designated for safety like the pressure relief valve that does not allow the system pressure to 
exceed the preset pressure and the check valve which ensures the flow only in the desired direction. Hydraulic components that affect dynamics of the circuit need to be models. These components are listed in the following:

\section{A. Hydraulic Pump}

A fixed positive displacement pump is used to flow high pressure fluid in the system. In a conventional hydraulic system, a variable displacement pump is more efficient since control of the displacement allows the adjustment of the flow to prevent the excess flow. Since an auxiliary motor can be used to capture the excess wind energy, using a fixed displacement is a smart because its price and maintenance costs are less than those of a variable displacement pump. Each pump has a theoretical displacement but based on its geometry and working pressure, a portion of the flow leaks back to the inlet port. The governing equation of a pump flow rate is described as follows [13-14]:

$$
Q_{p}=D_{p} \omega_{p}-\frac{C_{S} D_{p}}{\mu} P_{p}
$$

Where $Q_{p}$ is the actual delivered flow rate, $D_{p}, \omega_{p}$ and $P_{p}$ are the pump displacement, angular velocity and the differential pressure across the pump respectively. Cs and $\mu$ are the slippage coefficient and absolute viscosity. Cs is a constant term provided that the internal structure of a pump does not change [15]. Therefore, (1) can be re-written using the pump slippage coefficient $K_{p s}$ as follows:

$$
\begin{aligned}
& \mathrm{K}_{\mathrm{ps}}=\frac{\mathrm{C}_{\mathrm{s}} \mathrm{D}_{\mathrm{p}}}{\mu}(2) \\
& \mathrm{Q}_{\mathrm{p}}=\mathrm{D}_{\mathrm{p}} \omega_{\mathrm{p}}-K_{\mathrm{ps}} P
\end{aligned}
$$

The leakage is under influence of two mechanisms. The first mechanism is the laminar leakage due to pressure gradient in the clearance of the pump. The second mechanism is the flow loss due to compression and based on these mechanisms, different leakage models have been investigated in [16]. Laminar leakage exhibits a linear behavior which can also be experimentally proven [17-19]. This linear model has been frequently utilized in power transmission [14, 22], wherein pumps and motors rotate continuously and their speeds are usually moderate to high.

In trajectory tracking application, the motor's shaft position and direction are controlled. The leakage specifically at very low velocity can exhibit nonlinear behavior so that more accurate leakage model can be used [23]

\section{B. Variable displacement hydraulic motor}

Since the shaft speed of motor is controlled by its displacement, the motor can be controlled to deliver constant rotational shaft to the generator at any wind speed. This feature is especially important for the primary motor since it is connected to a synchronous generator that needs to be run at constant speed. The governing equation for the motor flow is similar to the pump's flow equation but with the motor leakage flow $K_{m s}$ as the additive term [13-14]:

$$
Q_{m}=D_{m} \omega_{m}+K_{m s} P_{m}
$$

where all of terms are similar to those of pump flow equation. $P_{m}$ is the pressure differential across the motor. Besides for motor, the torque equation can be written based on driving torque and braking torques applied to a hydraulic motor. Additional resistive terms are not considered in the following formulation [24] because their values are typically much less than the viscous term [13-14, 25]:

$I_{m} \frac{d \omega_{m}}{d t}=D_{m} P_{m}-C_{v} D_{m} \mu \omega_{m}-T_{l}$

where $I_{m}, P_{m}$ and $D_{m}$ are motor inertia, differential pressure across the motor and the motor displacement respectively. $C_{v}, \mu$ and $T_{\text {Load }}$ are viscous drag coefficient, absolute viscosity and load torque applied on the motor shaft respectively. A lumped coefficient can be used to replace the terms that multiplies to the motor velocity as the viscous damping coefficient and $B_{v}=C_{v} D \mu$.

\section{CAES Mathematical Modeling}

According to the CAES and wind power configuration, demonstrated in Figure 1, the excess mechanical energy from the prime mover is converted to compressed air in the tank and is released in form of mechanical torque on the generator shaft. In general CAES has three modules. The first module represents the compression stage, which converts the excess prime mover's mechanical energy to the mechanical energy of compressed air. The second module is the air tank for energy storage. The third module represents the expansion stage, which extracts the energy stored in the air to generated mechanical torque assisting the prime mover in meeting the power demanded from the generator.

For both the first and the third modules, heat exchangers are used to decrease the air temperature during the compression stage because for safety purpose, the air tank needs to keep a relatively low air temperature and temperature rises after being compressed by the compressor. On the other hand, after released from the air tank, to increase the efficiency of power conversion, heat exchangers are used to increase the air temperature before going through each expander. As illustrated in Figure 1, the hydraulic motor, generator and CAES are connected to the same shaft. 


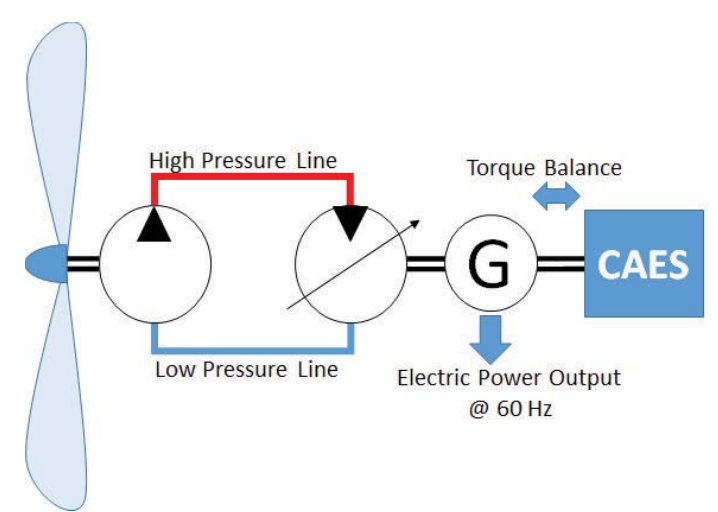

Fig. 1 Integration of hydraulic wind power transfer system with CAES.

\section{A. Compressor model}

To compress the air to the level required in the tank, a two stage compressor was considered. Therefore, the system consists of two air compressors with $85 \%$ efficiency and two heat exchangers with $70 \%$ efficiency in the compression stage. The compression ratio of the two compressors is 5 and 2.8, respectively. The temperature of the heat exchanger is set to $273 \mathrm{~K}$. The ambient temperature air is fed to the first stage compressor and is cooled down through a heat exchanger before entering the second stage. The air enters the second stage compressor, after which the highly compressed air is cooled down again by the second heat exchanger.

The compression process is stopped once the pressure inside the air tank reaches the maximum value of 200psi (13.79bar). The output air temperature of compressor and heat exchanger, the output air pressure of compressor are expressed in equations (6), (7), (8) and (9) respectively [26-28].

$$
\begin{aligned}
& \mathrm{T}_{\text {out }, \mathrm{c}}=\mathrm{T}_{\mathrm{in}, \mathrm{c}} \cdot \beta_{\mathrm{c}}^{\frac{\mathrm{n}-1}{\mathrm{n}}} \\
& \mathrm{T}_{\text {out }, \mathrm{HX}}=\mathrm{T}_{\text {out }, \mathrm{c}}+\eta_{\mathrm{HX}}\left(\mathrm{T}_{\mathrm{HX}}-\mathrm{T}_{\text {out, }}\right) \\
& \mathrm{p}_{\text {out }, \mathrm{c}}=\mathrm{p}_{\mathrm{in}, \mathrm{c}} \cdot \beta \\
& \mathrm{p}_{\mathrm{c}}=\frac{1}{\eta_{\mathrm{c}}} \dot{m}_{i n} \cdot c_{p} \cdot \mathrm{T}_{\mathrm{c}}^{\mathrm{in}}\left(\beta_{\mathrm{c}}^{\frac{\mathrm{n}-1}{\mathrm{n}}}-1\right)
\end{aligned}
$$

where $\mathrm{T}_{\mathrm{in}, \mathrm{c}}=293 \mathrm{Kand} \mathrm{T}_{\text {out }} \mathrm{c}, \mathrm{T}_{\mathrm{in}}, \mathrm{HX}$ and $\mathrm{T}_{\text {out }}, \mathrm{HX}$ are the air temperature entering and leaving compressors and that of heat exchangers, respectively. $\beta_{\mathrm{c}}$ is the compression ratio of each compressor. $\mathrm{n}$ is the polytropic index of the compressor train and is set as 1.4 and $(n-1) / n=0.2857$. $p_{\text {in, }, ~}$ and $p_{\text {out }, \mathrm{c}}$ are the air pressure entering and leaving compressors, $\eta_{\mathrm{c}}$ and $\eta_{\mathrm{HX}}$ are the efficiency of each compressor and heat exchanger, respectively. $\mathrm{T}_{\mathrm{HX}}$ is the temperature of the heat exchanger fluid and $\mathrm{Pc}$ is the energy consumed by each of the compressor. $\dot{m}_{\text {in }}$ is the air mass flow through compressors and cp is the specific heat at constant pressure.

\section{B. Storage tank model}

The air tank in this model is assumed to be above ground and without combustion chamber which depletes natural gas or oil. An important part of CAES is sizing the energy storage which is based on how much torque it has to provide to the generator's prime mover. In this model, the pressure of atmosphere air entering the compressor is $1 \mathrm{bar}$ and the leaving air pressure from the air tank set as $13.79 \mathrm{bar}$, so the maximum air pressure inside the air tank reaches $P_{\max }=13.79$ bar .

The lower limit of the air tank pressure is set to 2 bar under which the discharging mode is stopped. The temperature of the in-tank air is about $323 \mathrm{~K}$ after cooled by the second heat exchanger in the compression stage. To size for the air tank, the storage capacity of compressed air for the gas turbines to extract for supplying the torque required by the prime mover is determined based on the maximum accumulative power shortage over a continuous period during an one-hour simulation, by using mean wind speed of $6.5 \mathrm{~m} / \mathrm{s}$ with variance of $3.5 \mathrm{~m} / \mathrm{s}$. Power demand was also set to at $400 \mathrm{~kW}$ with variance of $200 \mathrm{~kW}$. The average value of the three simulation results is taken as the output energy of the gas turbine which equals to $27.8 \mathrm{kWh}$. Then the storage capacity, mass of air and volume inside the air tank are sized as in equations (10), (11) and (12) respectively [27].

$$
\begin{aligned}
& S \mathrm{C}=\frac{\text { Turb }_{\text {out }}}{\eta_{\mathrm{t}} b^{2}}(10) \\
& \mathrm{m}=\frac{3600 \mathrm{SC}}{\mathrm{c}_{\mathrm{p}}\left(\mathrm{T}_{\text {out }, \mathrm{ct}}-\mathrm{T}_{\text {in,ct }}\right)} \\
& \mathrm{V}=\frac{\mathrm{mRT}_{\mathrm{s}}}{p_{\mathrm{m}}}(12)
\end{aligned}
$$

where $p_{\max }$ is the maximum pressure inside the air tank, $\mathrm{SC}$ is the air tank storage capacity, Turb out $_{\text {in }}$ is the gas turbine power in $\mathrm{kWh}, \eta_{t}$ is the efficiency of each gas turbine, and $T_{i n, c t}$ and $T_{\text {out }, c t}$ are input and output air temperature through the compressor train. $T_{s}$ is the storage air temperature inside the tank. $V$ is the tank volume and $R$ is the air constant.

\section{Expander model}

The expansion stage of the CAES is composed of two turbines, i.e. a high pressure turbine (HPT) and a low pressure turbine (LPT) with efficiency both of $80 \%$, and two heat exchangers with efficiency both of $70 \%$. The compression ratios of the turbines are 3 and 4.6, respectively. The temperature of the heat exchanger is set to $480 \mathrm{~K}$. After released from the air tank, the air temperature is initially increased, through the first heat exchanger, before entering the HPT. The same process is performed for the second heat exchanger and the LPT. The expansion stage is a reverse process of the compression stage and the air temperature and pressure outputs of the each turbine, the temperature after each heat exchanger can be calculated as in equations (13), (14), (15) and (16) respectively [26-28].

$$
\begin{aligned}
& T_{\text {out }, \mathrm{t}}=\frac{T_{\text {in,t }}}{\beta^{\frac{k-1}{k}}}(13) \\
& \mathrm{T}_{\text {out }, \mathrm{HX}}=\mathrm{T}_{\text {out }, \mathrm{t}}+\eta_{\mathrm{HX}}\left(\mathrm{T}_{\mathrm{HX}}-\mathrm{T}_{\text {out, },}\right)_{(14)}
\end{aligned}
$$




$$
\begin{aligned}
& \mathrm{p}_{\text {out }, \mathrm{t}}=\frac{\mathrm{p}_{\mathrm{in}, \mathrm{t}}}{\beta} \\
& \mathrm{p}_{\mathrm{r}}=\eta_{\mathrm{t}} \dot{m}_{\text {out }} 3.5 R \cdot \mathrm{T}_{\mathrm{t}}^{\mathrm{in}}\left(1-\beta_{t}^{\frac{k-1}{k}}\right)(16)
\end{aligned}
$$

where $\beta_{t}$ is the compression ratio of each turbine, $\eta_{t}$ is the efficiency of each turbine and $\dot{m}_{\text {out }}$ is the air mass flow going through gas turbines from the air tank. $P_{t}$ is the power generated by each gas turbine.

\section{Simulation Results}

The integrated wind power system is simulated for one hour operation in which the wind speed is changed according to what is shown in Figure 2 at mean of $6.5 \mathrm{~m} / \mathrm{s}$ and a variance of $3.5 \mathrm{~m} / \mathrm{s}$.Figure 3 shows the profile of time varying power demand of users with a mean of $400 \mathrm{~kW}$ and a variance of $200 \mathrm{~kW}$.

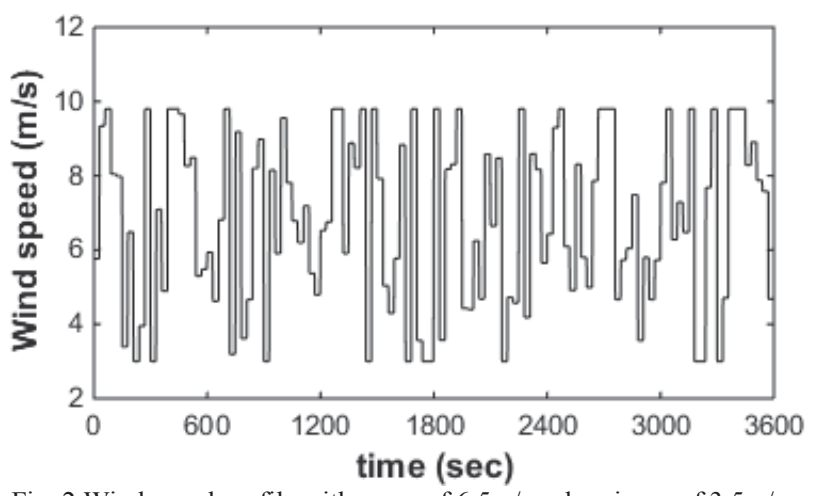

Fig. 2 Wind speed profile with mean of $6.5 \mathrm{~m} / \mathrm{sand}$ variance of $3.5 \mathrm{~m} / \mathrm{s}$

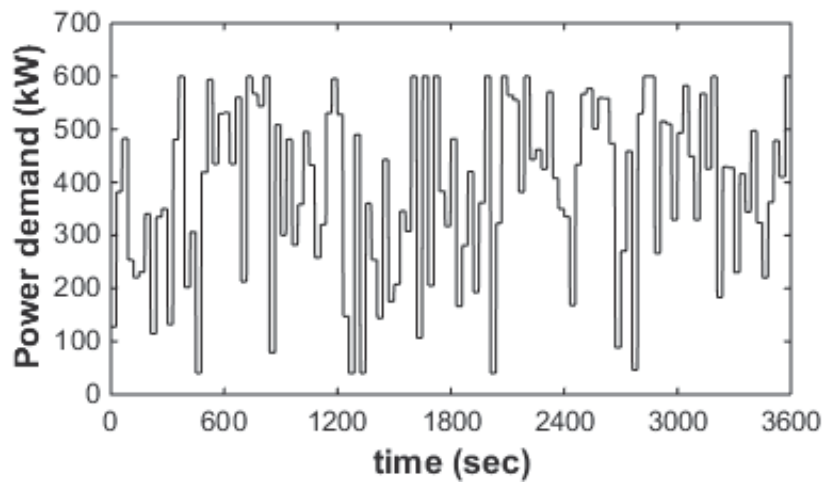

Fig. 3 Power demand profile with mean of $400 \mathrm{~kW}$ and variation of $200 \mathrm{~kW}$

Figure 4 illustrates the comparison of power insufficiency with and without the presence of CAES. It can be seen that when wind speed is low, it is hardly possible for the wind power system to satisfy the high power demand by itself. Although the initial air pressure was set to the lowest point of 2 bar, it only takes less than 50 second for CAES before it starts to keep providing full compensation for power shortage to meet power demand during the simulation. The simulation result demonstrates that CAES largely assists in mitigating the power demand fluctuations under severe wind variations.

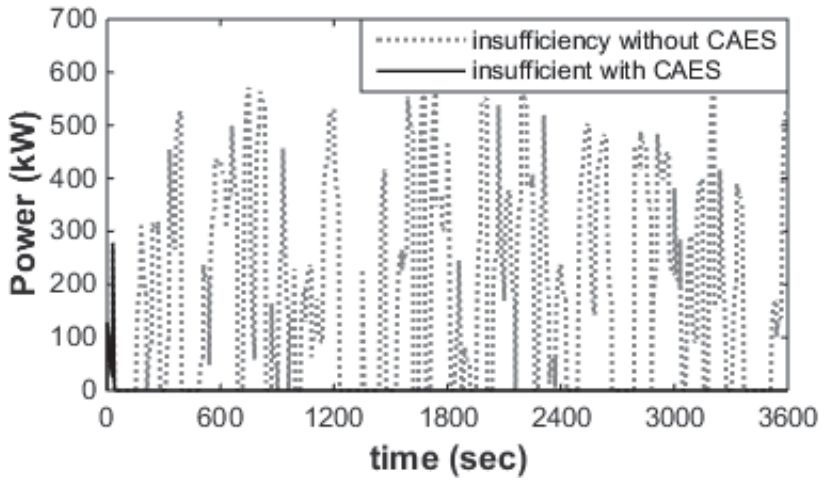

Fig. 4 Comparison of insufficient power with and without the aid of CAES

Figure 5 shows the time evolution of air pressure inside the storage tank, which indicated that the tank air pressure dynamically follows the power balance of the system. It is maintained within limits of 2 bar and 13.79 bar under charge and discharge modes of CAES.

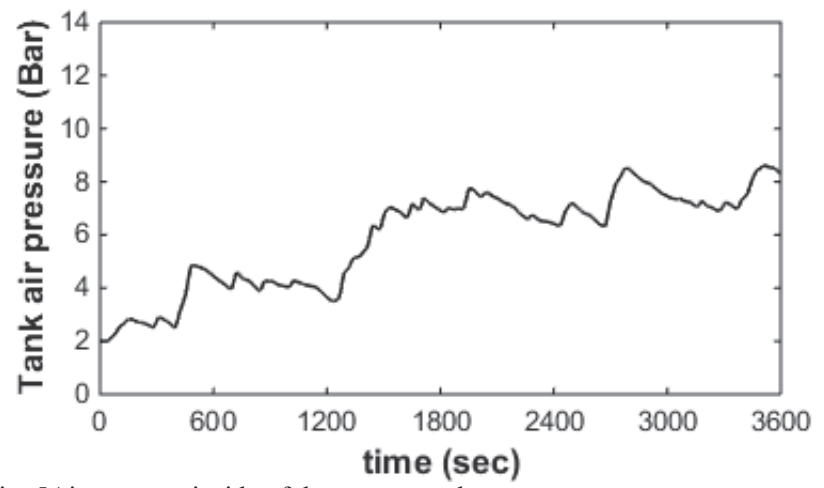

Fig. 5Air pressure inside of the storage tank

The generator speed profile is shown in Figure 6. This figure illustrates that the rotating speed of the hydraulic motor is maintained stable around 900rpm with the presence of CAES during the simulation, regardless of variable wind speed and power commands. The stable rotor speed directly contributes to the continuous supply of $60 \mathrm{~Hz}$ electricity power by a four-pole generator which is connected to the common shaft with the hydraulic motor.

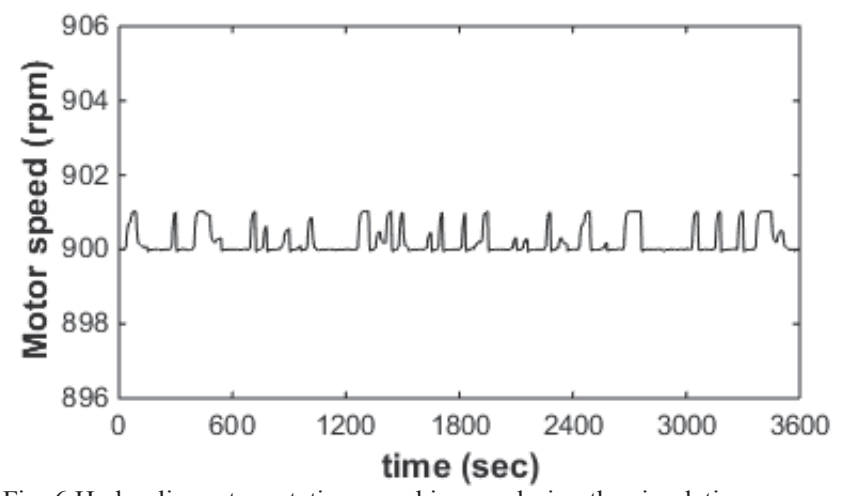

Fig. 6 Hydraulic motor rotating speed in rpm during the simulation

\section{CONCLUSION}

In this paper, CAES system has been integrated with a hydraulic wind power system to assist in torque production 
under various wind speeds and power demands. The simulation results show that CAES is capable of compensating for insufficient power by transferring compressed air energy to the power system while keeping the air tank pressure under the operation range. With the air the CAES, the hydraulic wind power system is expected to not only meet the power demand fluctuations, but also it can maintain a constant power delivery at a stable frequency.

\section{REFERENCES}

[1] A. Izadian, N. Girrens, P. Khayyer, "Renewable Energy Policies, A Brief Review of the Latest U.S. and E.U. Policies," IEEE Industrial Electronics Magazine, vol. 7, issue 3, September 2013.

[2] S. Hamzehlouia, A. Izadian, "Nonlinear State Space Modeling of Gearless Wind Power Systems," IECON 2012, pp. 1098-1103.

[3] M. Vaezi and A. Izadian, "Piecewise Affine System Identification of a Hydraulic Wind Power Transfer System," Control Systems Technology, IEEE Transactions on, Accepted, 2014.

[4] M. Vaezi and A. Izadian, "Multiple-Model Adaptive Estimation of a Hydraulic Wind Power System," in Industrial Electronics Society, IECON 2013-39th Annual Conference of the IEEE, Vienna, Austria,2013, pp. 2111-2116

[5] S. Eriksson, H. Bernhoff, and M. Leijon, "Evaluation of Different Turbine Concepts for Wind Power," Renewable and Sustainable Energy Reviews, vol. 12, issue 5, pp. 1419-1434, June 2008.

[6] Afshin Izadian, US Patent 8,878,384, Central wind turbine power generation, Nov. 04, 2014.

[7] http://www.chapdrive.com/technology/5-mw-project

[8] http://www.mhps.com/en/news/20160119.html.

[9] H. Ibrahim, A. Ilinca, and J. Perron. Energy Storage Systems Characteristics and Comparisons. Renewable and Sustainable Energy Reviews, 12(5): 1221 - 1250, 2008.

[10] S. Succar and R. H. Williams. Compressed Air Energy Storage: Theory, Resources and Applications for Wind Power. Technical report, Princeton, New Jersey, April 2008.

[11] E.ON. Presentation of the Huntorf CAES Plant.www.kraftwerkwilhelmshaven.com/pages/ekW_de/Huntorf/Uebersicht/index.htm, last retrieved 3 December 2010.

[12] Power South. Presentation of the McIntosh CAES Plant. www.powersouth.com/mcintosh_power_plant, last retrieved 3 December 2010.

[13] Merritt, H.E., Hydraulic control systems. 1967: J. Wiley.

[14] Fitch, E. and I. Hong, Hydraulic component design and selection. BarDyne. 2001, Inc.

[15] Blackburn, J.F., Fluid power control. 1969: Mit Press.

[16] K.-E. Rydberg, Efficiencies for variable hydraulic pumps and motorsEfficiencies for variable hydraulic pumps and motors. Sweden: Linköpings University, Department of Management and Engineering, 2009.

[17] B. Rexroth, "Fixed Displacement Pump A4FO," ed, 2013.

[18] E. Vickers, "Hydrokraft Transmission Piston Pumps," in Technical catalogu, ed, 2013.

[19] Parker, "Denison GOLD CUP® Product Catalog Piston Pumps \& Motors," in HY28-2667-01/GC/NA,EU, ed, 2010

[20] E. C. Fitch, Hydraulic component design and selection: Bardyne. Incorporated, 2004.

[21] N. Manring, Hydraulic control systems: John Wiley \& Sons Incorporated, 2005.

[22] J. Schmitz, M. Vukovic, and H. Murrenhoff, "Hydrostatic Transmission for Wind Turbines: An Old Concept, New Dynamics," in ASME/BATH 2013 Symposium on Fluid Power and Motion Control, 2013, pp. V001T01A029-V001T01A029.

[23] J. Yao, Z. Jiao, D. Ma, and L. Yan, "High-accuracy tracking control of hydraulic rotary actuators with modeling uncertainties,"IEEE/ASME Transactions on Mechatronics, vol. 19, no. 2, pp. 633-641, Apr. 2014.

[24] S. Gao and N. Zhang, "A review of different methodologies for solving the problem of wind power's fluctuation," in Sustainable Power Generation and Supply, 2009. SUPERGEN'09. International Conference on, 2009, pp. 1-5.
[25] Gorbeshko, M., Development of Mathematical Models for The Hydraulic Machinery of Systems Controlling the Moving Components. Hydrotechnical Construction, 1997. 3(12).

[26] Fernando De Samaniego Steta, "Modeling of an Advanced Adiabatic Compressed Air Energy Storage (AA-CAES) Unit and an Optimal Model-based Operation Strategy for its Integration into Power Markets", Swiss Federal Institute of Technology (ETH) Zurich, October 2010.

[27] M. M. El-Wakil, "Energy Storage," in Power plant Technology, International ed. Singapore: McGraw-Hill, 1988, ch.16, sec. 2, pp. 680685.

[28] N. S. Hasan, "Mathematical Model of Compressed Air Energy Storage in Smoothing 2MW Wind Turbine." IEEE: 5. Pdf 